\title{
High-Radiance LED-Driven Fluidized Bed Photoreactor For The Complete Oxidation of n-hexane In Air
}

Carlos J Bueno-Alejo, ${ }^{\mathrm{a}, \mathrm{b}}$, Jose L. Hueso ${ }^{\mathrm{a}, \mathrm{b}}$, Reyes Mallada, ${ }^{\mathrm{a}, \mathrm{b}}$, Ignacio Julian ${ }^{\mathrm{a}, \mathrm{b}}$ and Jesus Santamaria $^{* a, b}$

${ }^{a}$ Institute of Nanoscience of Aragon and Department of Chemical Engineering and Environmental Technology C/ Mariano Esquillor, s/n, 50018, Zaragoza (Spain).

${ }^{b}$ Networking Research Centre of Bioengineering, Biomaterials and Nanomedicine (CIBER-BBN), C/ Monforte de Lemos, 3-5 Pabellón 11, 28029 Madrid, (Spain).

*E-mail corresponding authors: jesus.santamaria@unizar.es

KEYWORDS: Photocatalysis; VOCs remediation; LEDs; Fluidized-bed reactors; P25

\begin{abstract}
This work presents a highly efficient photo-reactor configuration for VOC abatement. It consists of a fluidized bed made of commercial, easy to fluidize, transparent borosilicate glass beads coated with commercial $\mathrm{TiO}_{2}$ nanoparticles ( 0.15 to $2.3 \mathrm{wt} \%$ loadings). Herein, we demonstrate that the use of high-radiance/low consumption UV-LEDs as irradiation sources with a deeper light penetration under fluidizing conditions facilitates the photocatalytic response to achieve the complete oxidation of VOCs. The role of different parameters such as catalyst loading and irradiation power have been thoroughly studied and evaluated to maximize the full combustion of n-hexane. Under the high radiance (up to $2200 \mathrm{~mW} / \mathrm{cm}^{2}$ ) conditions used the bed heats significantly (up to $190{ }^{\circ} \mathrm{C}$ ), although this did not have an effect on the conversions reached, which
\end{abstract}


depended solely on the wavelength and power used. The productivity of the photoreactor tested and the space velocity used were around $5.25 \times 10^{-2} \mathrm{~mol} / \mathrm{g} \cdot \mathrm{h}$ and $12000 \mathrm{~h}^{-1}$ respectively.

\section{Introduction}

Organic compounds from a variety of sources have become common pollutants in air, giving rise to important environmental and health concerns[1-5]. These organic molecules are mostly anthropogenic and can induce several respiratory diseases[1, 2]. In particular volatile organic compounds (VOCs) present in industrial effluents, vehicle emissions and also in indoor ambient are considered very harmful and top-ranked on the list of air pollutants. When using catalytic combustion for their removal high temperatures and/or pressures are required for their complete oxidation. For instance, Zalamea et al. performed the oxidation of methyl ethyl ketone (MEK) using catalytic membranes and temperatures around $200{ }^{\circ} \mathrm{C}$ were needed to fully oxidize the pollutant[6]. Likewise, using a flow reactor, Mével et al. required temperatures in the range of $150-750{ }^{\circ} \mathrm{C}$ with pressures of $20-100 \mathrm{kPa}$ to oxidize n-hexane diluted in $\mathrm{N}_{2}$ [7]. Likewise, the use of reactor configurations with structured catalysts has been evaluated in order to reduce pressure drop and improve the oxidation of VOCs. The full oxidation of several VOCs was attained supporting Pt over $\mathrm{Al}_{2} \mathrm{O}_{3} / \mathrm{Al}$ monoliths at temperatures in the $200-250^{\circ} \mathrm{C}$ range [8]. While these temperatures can be considered as moderate, they still entail a significant economic penalty, since the whole air stream must be brought up to the desired temperature and pressures in order to remove VOC concentrations that are in the tens or hundreds of ppm range, thereby not providing enough heat in their combustion to reach the required temperatures. In order to use milder reaction conditions, many efforts have been devoted to catalyst development, mainly through 
noble-metal nanoparticle catalysts supported on different metal oxides[9, 10], or mesoporous silica[11] that successfully lowered the total oxidation of n-hexane at temperatures below $200{ }^{\circ} \mathrm{C}$. In spite of the excellent stability and selectivity of Pt-based catalysts, the high cost of precious metals has prompted the search for: (i) lower cost catalysts based on more abundant and affordable transition metal oxides or semiconductors[12] and (ii) the development of novel reactor configurations equipped with alternative excitation sources to selectively activate and oxidize VOCs under milder conditions. Among these, it is worth mentioning the use of plasma discharges[13], microwaves and radiofrequency[14], microreactors[15, 16] or photoreactors irradiated with UV-light sources[17-20].

In particular, photooxidation methods are recently being advocated over the previous methodologies due to the use of mild conditions to achieve the degradation of organic pollutants[21, 22]. Photocatalysis represents a greener way to perform reactions that would require a much higher input of energy if carried out under conventional heating. Photooxidation processes use mainly semiconductor materials as catalysts. Since the pioneering work of Fujishima and Honda using $\mathrm{TiO}_{2}$ for the photolysis of water[23] , many authors have tried to use semiconductors for the photooxidation of organic molecules. In particular, multiple efforts have been undertaken to deplete VOCs in the presence of $\mathrm{TiO}_{2}$ under UV light from xenon or mercury lamps as energy sources[2428]. Typically these lamps exhibit a low irradiation and energy efficiency making it difficult to completely degrade VOCs such as n-hexane. Furthermore, a long-term use of these catalysts is hindered by the generation of carbonaceous, (and in some cases toxic), by-products on the surface of the catalyst that lower their efficiency and limit their use in industrial applications[29, 30]. These incomplete degradation of alkanes have been thoroughly studied in previous works describing the oxidation mechanism 
and the different by-products obtained[7, 24, 31]. Another issue that prevents a wider use of photocatalytic processes relates to the inherent difficulty in scaling up laboratorydeveloped processes. In most of the previously reported works, the use of fixed bed reactor configuration has normally led to less efficient catalyst utilization. This fact has been attributed to the limited penetration of light inside the bed[32, 33]. Alternatively, when the photocatalyst is deployed as a thin film, excellent illumination is achieved, but huge reactor areas are required to obtain meaningful conversions[34]. As a compromise, the use of bubbling fluidized bed reactors (FBRs) was early proposed to overcome these problems[35-38]. The bubble phase in FBRs facilitates a deeper penetration of light and the intense mixing provided by fluidization induces a continuous renewal of the catalyst at the illuminated surfaces[39-41].

Nowadays, light emitting diodes (LEDs), which convert more efficiently electricity into light and with long lasting periods, are replacing conventional bulb lamps and are becoming more relevant in process intensification carried out by photoreactors[42, 43]. The reduced size of LEDs and the possibility to arrange them into tailored arrays open the possibility for the design of different reactor configurations. Also, the recent developments in the fabrication of high intensity LED sources that can be modulated from a few $\mathrm{mW} / \mathrm{cm}^{2}$ to several $\mathrm{W} / \mathrm{cm}^{2}$ and, more significantly, the fact that all the light power is emitted in a narrow wavelength range, in contrast to the above-mentioned conventional light sources, makes this irradiation source a way to revolutionize the photocatalytic applications towards industrial implementation.

A former example combining LED technology and fluidized bed reactor for photocatalytic oxidation of methyl ethyl ketone was presented by Hajaghazadeh et al.[44]. The configuration for the reactor consisted of a rectangular flat plate fluidized bed reactor illuminated from both sides with arrays of 80 low intensity LEDs which 
resulted in a radiation intensity of $90 \mathrm{~mW} / \mathrm{cm}^{2}$. In this work we propose the use of high power LED technology in a FBR to successfully achieve the total photo-oxidation of nhexane, as a known VOC aliphatic model with limited reactivity in comparison with other linear counterparts (i.e. ketones, acetaldehydes).

\section{Materials and Methods}

\subsection{Materials}

$\mathrm{TiO}_{2}$ (P25) was supplied by Evonik, ethanol (Absolut PRS) was purchased from Panreac and borosilicate glass beads were obtained from Abrasivos y Maquinarias S.A.

\subsection{Catalyst preparation}

The catalyst consists of commercial $\mathrm{TiO}_{2}$ P25 particles $\left(\sim 21 \mathrm{~nm}\right.$ crystal size, $50 \mathrm{~m}^{2} / \mathrm{g}$ specific surface area) impregnated over glass beads with an average diameter of ca. 90 $\mu \mathrm{m}$. Different catalyst loadings, $0.15,0.9,1.4$ and $2.3 \%$ were obtained by adding different amounts of P25 suspended in ethanol to $500 \mathrm{mg}$ of glass spheres and letting the solvent evaporate slowly under gentle manual stirring. After most of the solvent was evaporated a viscous slurry was formed. The solid was subsequently introduced in an oven at $80{ }^{\circ} \mathrm{C}$ for 12 hours. The synthesis of the photocatalysts has been performed at the platform of Production of Biomaterials and Nanoparticles of the NANBIOSIS ICTS, Spain.

\subsection{Characterization techniques}

The morphology and chemical distribution of the photocatalytic P25-glass bead hybrids were characterized by field-emission scanning electron microscopy (SEM) equipped with an energy-dispersive x-ray spectroscopy (EDX) detector using a FEI Inspect instrument. The surface morphology and Z-heights of the supported glass beads was 
characterized by atomic force microscopy (AFM) using a Multimode 8 Veeco (Bruker) in a non-contact mode.

\subsection{Hydrodynamics study}

Experimental solids mixing tests were conducted with phosphorescent particles, i.e. EuDy/SrAl2O4, as optical tracers and uncoated glass beads in order to gain insight into the fluid dynamic regime within the fluidized photocatalytic bed and to determine the axial mixing rate between initially segregated particles (Figure S.4). Solids mixing tests were recorded within a dark box in order that the luminiscence of the optical tracers contrasts with the low pixel intensity of the non-emitting glass beads. Pure N2 was employed as fluidization gas. Image post-processing was performed with the aid of the Image Processing Toolbox of Matlab 2015b. An in-house developed algorithm similar to that employed by Julián et al.[45, 46] was used to select single video frames, crop the resulting images, analyze the pixel intensity throughout the regions of interest and bring out local-averaged intensities, i.e. tracer concentrations, along the vertical position in the bed for each mixing time. Pixel intensities were normalized into [0-1] scale in order that the area under every tracer concentration curve, $\mathrm{C}(\mathrm{z}, \mathrm{t})$, remains the same taking into account the tracer emissivity loss along the mixing time. The Mixing index parameter was directly derived from $\mathrm{C}(\mathrm{z}, \mathrm{t})$ and indicates the degree of axial mixing between initially segregated particles along the mixing test. For the employed fluidized bed and gas throughput, Figure S.4.e suggests that the complete mixing is reached within some seconds on stream, thus illustrating the proper mixing regime.

\subsection{Photocatalysis tests}

Figure 1 and Figure S2 shows a schematic description of the experimental setup designed to carry out the illumination and photocatalytic degradation of n-hexane. The

reaction was conducted in a home-made system comprising a quartz cell with 
rectangular shape $(50 \times 10 \times 5 \mathrm{~mm}$ (height $\times$ width $\times$ length) purchased from Teknokroma). The glass beads impregnated with P25 were loaded in the reactor forming a homogeneous bed $(1 \mathrm{~cm}$ high) on top of a fixed bed containing larger (200$400 \mu \mathrm{m})$ uncoated glass spheres that served as a distributor of the gas flow to enable an effective fluidization of the photocatalyst. The cell was simultaneously illuminated by two high power (4.5 W) $365 \mathrm{~nm}$ LEDs (purchased from LedEngin) coupled to a Synjet ${ }^{\circledR}$ cooling system. Other alternative high power LED were employed with different wavelength and output powers: $405 \mathrm{~nm}(3.9 \mathrm{~W}), 460 \mathrm{~nm}(2.2 \mathrm{~W}), 530 \mathrm{~nm}(10$ $\mathrm{W}), 740 \mathrm{~nm}(2.1 \mathrm{~W})$ and $940 \mathrm{~nm}(3.2 \mathrm{~W})$. The LEDs were positioned at $1 \mathrm{~mm}$ from the wall of the cell to ensure a good illumination of the whole photocatalyst bed (Figure 1). Different light irradiances were used, ranging from 7 to $2200 \mathrm{~mW} / \mathrm{cm}^{2}$ (irradiance calculations based on LED specifications and experimental set up), using a programmable power supply unit (ISO-TECH, IPS-405,0-40V) to set the different LED powers. The bed temperature was simultaneously monitored with the aid of a thermocouple placed inside the catalyst bed and an infrared thermographic camera (NEC InfRec R300RS) operating in the spectral range of 8 to $14 \mu \mathrm{m}$. This IR camera determined the temperature in the external reactor walls (emissivity value of 0.92 ), within a range between $-40{ }^{\circ} \mathrm{C}$ and $+500{ }^{\circ} \mathrm{C}$. Temperature inhomogeneities were negligible within the photocatalyst bed and corroborated the expected heat transfer efficiency of the FBR. The photocatalytic experiments were performed with a total flow of $100 \mathrm{~mL} / \mathrm{min}$ of gas containing $200 \mathrm{ppm}$ of n-hexane (or $200 \mathrm{ppm}$ of benzene and 58 ppm toluene) in air to ensure a homogeneous fluidization of the photocatalyst bed (relative gas velocity, $\mathrm{u}_{\mathrm{gas}} / \mathrm{u}_{\mathrm{mf}}=2$ ). Due to the discrepancies found in the literature about the effect of water on photocatalytic gas phase reactions we did not include it in our inlet stream and focus the discussion in illumination and fluidization conditions of the 
photoreactor[47, 48]. The inlet final concentration of n-hexane was achieved upon mixing with the proper flow rates, n-hexane in $\mathrm{N}_{2}, \mathrm{O}_{2}$ and synthetic air (all purchased from PRAXAIR España S.L.U.), in order to get the different total flow rates assessed. After an equilibration period of 30 min that served us to evaluate the dark adsorption of n-hexane in the catalyst, the LED lights were turned on for different time intervals and the gas effluent outlet analysed by gas chromatography (Agilent 3000 Micro GC). Two modules with OV-1 and PPQ columns, each one of them attached to a thermal conductivity detector (TCD), were employed to separate and detect the different gas compounds. The steady state final concentration achieved was always $\leq 10 \mathrm{ppm}$ of $\mathrm{n}$ hexane when maximum LED power was used and this steady-state was always achieved within minutes regardless of the experimental settings. Under the conditions used, the nhexane detection limit was $3 \mathrm{ppm}$. Maximum error in the mass balance closures for carbon and oxygen in this work was $\pm 2 \%$. Because of this, significant generation of undetected byproducts is unlikely. Before discharge, the exit of the fluidized bed reactor was passed through a bubbler to trap potentially entrained nanoparticles. 


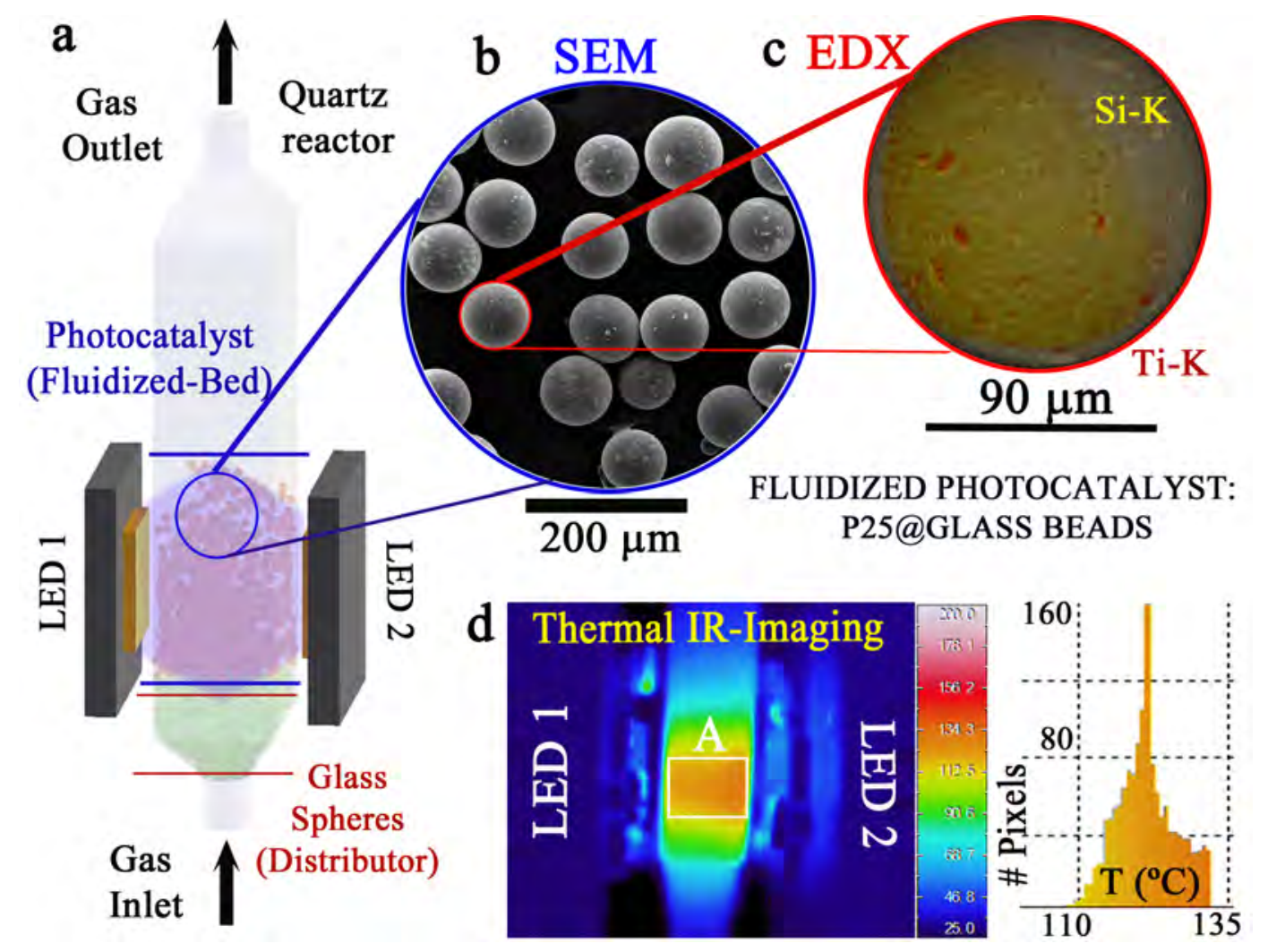

Figure 1. Description of the experimental setup: a) Scheme describing the different parts of the fluidized bed photoreactor; b) SEM image of fluidizable photocatalyst made of P25 impregnated glass beads; c) EDX mapping corresponding to a magnification of one of the individual glass bead displayed in (b) merging the Si-K signal (yellow color) corresponding to the glass beads and the Ti-K contribution of the decorating P25 nanoparticles (red color); d) Side thermal image of the wall of the photocatalytic reactor irradiated with LEDs under reaction conditions acquired with an Infrared camera. The histogram corresponds to the temperature distribution for the labeled area A that corresponds to the volume occupied by the fluidized photocatalytic bed.

\section{Results and Discussion}

3.1. Performance of the high irradiance UV-LED photo-reactor with a fluidized bed configuration 
Figures 1b-1c shows the appearance of the catalyst after impregnation of the support glass beads with P25 (more SEM images available in supporting information). In order to achieve a proper fluidization regime, the borosilicate glass beads were previously sieved and selected within the $90-110 \mu \mathrm{m}$ diameter range (Figure 1b). Taking into account their density $\left(\rho_{\mathrm{GB}}=2.55 \mathrm{~g} / \mathrm{cm}^{3}\right)$ and size, these particles lay in the A-B boundary of Geldart's classification and, thus, fine bubbling fluidization occurs at high gas velocities. On this regard, the hydrodynamic analysis performed for the employed fluidized bed using a gas throughput ugas/umf $=2.0$ indicates proper particles circulation along the bed. Defluidized regions (dead bed zones) were not detected at this gas velocity, thus, illustrating good gas-solid contact. The fluidization time until complete mixing of initially segregated particles, i.e. optical tracers and glass beads, was quantified to be around 20 seconds (Figure S.4.e). Then, impregnation with P25 was carried as described in the previous section (vide supra). Figure 1c shows a representative EDX mapping distribution of the Si and Ti signals labelled in yellow and red colors corresponding to an individual glass bead coated with P25 nanoparticles.

The high irradiance coupled to the bubbling fluidization regime ensured a good penetration of light through the catalyst bed. It is noteworthy that the maximum conversion observed in each point measured was achieved after a very short stabilizing period (few minutes range), in contrast to more extended periods reported in the literature for n-hexane in non-fluidized bed typically implying hours [25, 49, 50]. Besides, the high power LEDs delivered an intense flux of photons to the catalyst, generating a high density of charge carriers on the surface, able to react with the VOC pollutant. Upon excitation with UV light, valence band electrons are promoted to the conduction band and create positive charges behind. The bulk recombination of those charges is partly prevented by the small size of the $\mathrm{TiO}_{2}$ crystals and their high specific 
surface area. Also, even though recombination of electron and holes will take place to a certain extent, the high intensity of the incident light source still promote and maintain a high charge-carrier concentration. This level will be enough to oxidize the n-hexane molecules adsorbed on the photocatalyst surface. An indirect proof of this hypothesis was provided by the relatively high steady-state temperatures (above $150{ }^{\circ} \mathrm{C}$, see figure 1d) reached on the fluidized solid under illumination with UV LED, as measured directly by a thermocouple inserted in the bubbling zone and confirmed by the IR thermographic camera readings of the temperature distribution at the reactor wall (Figure 1d). This catalyst heating is likely generated by the thermal relaxation of those charge carriers that do not take part in the photooxidation of n-hexane. As it will be shown later, this temperature increase does not have a significant effect in the reaction, meaning that all the observed conversion is achieved via pure photocatalytic events. This sole photocatalytic effect contrasts with other systems where an energy input (i.e. in the form of heat), needs to be provided in order to assist the oxidation of the pollutant[47], thereby increasing the complexity and cost of the VOCs degradation.

\subsection{Effect of catalyst loading}

Different weight loadings of P25 NPs onto the glass beads were assessed ranging from 0.15 to $2.3 \%$ wt., which correspond to total catalyst weights ranging between a total of $0.8 \pm 0.1$ and $13 \pm 0.1 \mathrm{mg}$ of $\mathrm{P} 25$ deposited on the glass beads in the reactor. Figure $2 \mathrm{a}$ shows that the fluidized bed catalysts were highly efficient in promoting VOC conversion. Only when the catalyst loading was reduced down to $0.15 \%$ wt. full conversion was not approached although, even in this case, more than $70 \%$ of conversion was achieved. In comparison with previous works reported in the literature 
(see Table 1), an important decrease in the amount of catalyst was required in our case to oxidize the n-hexane used as model VOC (Figure 2a).

Remarkably, an amount as low as $4 \mathrm{mg}$ of photocatalytic phase was necessary to complete the total oxidation of the n-hexane in our photoreactor with a gas hourly space velocity (GHSV) of $12000 \mathrm{~h}^{-1}$. Although it is difficult to compare with previous results, because some key data are often missing in the reported literature, we have found a series of works with analogous experimental configurations and/or VOC selection to establish a meaningful comparison. Table 1 shows the reaction rate values achieved for other VOCs in several fluidized bed photoreactors and also for the abatement of $n$ hexane in other reactor configurations. The specific reaction rate found in this work for n-hexane was more than 20 times higher even when compared to MEK, a VOC that is usually considered easier to degrade than any alkane due to the presence of oxygencontaining functional groups[6]. The differences are even higher when compared to works with n-hexane as the target molecule for photocatalytic degradation. Additional experiments for the degradation of benzene (200 ppm) and toluene (58 ppm), using one of the catalyst synthesized in this work (1.4\% loading) were performed. The goal was to evaluate the potential expansion of the use of this photoreactor to other VOC compounds. In this case, both pollutants were present simultaneously on the stream, so the carbon concentration in the inlet gas was higher that in the case of n-hexane experiments (ca. 30\%). With this in mind, and even with the possible competition between them, conversions of 55\% (benzene) and 90\% (toluene) were achieved for benzene and toluene, respectively (Fig S3). The higher conversion in the case of toluene can be attributed to its preferential adsorption on $\mathrm{TiO}_{2}$, as shown in the study of Nagao et al. on the adsorption of benzene, toluene and chlorobenzene on $\mathrm{TiO}_{2}[51]$. 
Table 1. Overview of some similar VOC-oxidation photocatalytic reactor performances reported in the literature

\begin{tabular}{|c|c|c|c|c|c|c|c|c|c|c|}
\hline Catalyst & $\begin{array}{l}\text { Irradiation } \\
\text { source }\end{array}$ & Pollutant & $\begin{array}{c}\text { Pollutant } \\
\text { Concentration } \\
(\text { ppm })\end{array}$ & $\begin{array}{c}\text { Conversion } \\
(\%)\end{array}$ & $\begin{array}{l}\text { Catalyst } \\
\text { Mass (g) }\end{array}$ & $\begin{array}{c}\text { Residence } \\
\text { time } \\
(\mathrm{L} / \mathbf{g} \cdot \mathbf{h})\end{array}$ & $\begin{array}{c}\text { GHSV } \\
\left(h^{-1}\right)\end{array}$ & $\begin{array}{l}\text { Reactivity*10 } \\
\left(\text { mol }_{\text {n-hexane }} / \mathrm{g} \cdot \mathrm{h}\right)\end{array}$ & $\begin{array}{c}\text { Additional } \\
\text { Experimental } \\
\text { Remarks }\end{array}$ & Ref. \\
\hline PC500 & UV LEDs & MEK & 250 & 82 & 0.14 & 357 & 2500 & 2.4 & $\begin{array}{l}\text {-Fluidized } \\
\text { bed reactor } \\
-\mathrm{T}^{\mathrm{a}}=120^{\circ} \mathrm{C}\end{array}$ & [44] \\
\hline $\mathrm{TiO}_{2}$ & UV Lamp & MEK & 800 & 98 & 7.4 & 8 & 8268 & 0.27 & $\begin{array}{l}\text {-Fluidized } \\
\text { bed reactor }\end{array}$ & [52] \\
\hline $\mathrm{TiO}_{2}$ & UV Lamp & TCE & 67 & 48.8 & 0.35 & 49 & 17040 & 0.066 & $\begin{array}{l}\text {-Fluidized } \\
\text { bed reactor }\end{array}$ & [37] \\
\hline $\mathrm{TiO}_{2}$ & Optical fiber & TCE & 151 & 86.8 & 0.1 & 64 & 220 & 0.34 & $\begin{array}{l}\text {-Fluidized } \\
\text { bed reactor }\end{array}$ & [53] \\
\hline $\begin{array}{c}\mathrm{Ag}-\mathrm{V}- \\
\mathrm{TiO}_{2}\end{array}$ & $\begin{array}{l}\text { White light } \\
\text { bulb }\end{array}$ & n-hexane & 100 & 93.7 & - & - & 50 & - & $\begin{array}{l}\text { Monolithic } \\
\text { foam reactor }\end{array}$ & [50] \\
\hline $\mathrm{TiO}_{2}$ & UV Lamp & n-hexane & 1000 & 1 & 0.35 & 42.9 & 1500 & 0.017 & $\begin{array}{c}\text { Parallel flow } \\
\text { reactor } \\
-T^{\mathrm{a}}=150^{\circ} \mathrm{C}\end{array}$ & [29] \\
\hline $\mathrm{TiO}_{2}$ & UV Lamp & n-hexane & 470 & 30 & 0.3 & - & 4000 & - & $\begin{array}{l}\text {-Continuous } \\
\text { fix-bed flow } \\
\text { microreactor }\end{array}$ & [49] \\
\hline P25 & UV LED & n-hexane & 200 & 80 & 0.00075 & 8000 & 12000 & 52.5 & $\begin{array}{l}\text {-Fluidized } \\
\text { bed reactor }\end{array}$ & $\begin{array}{l}\text { This } \\
\text { work }\end{array}$ \\
\hline P25 & UV LED & n-hexane & 200 & 95 & 0.0045 & 1333.3 & 12000 & 9.8 & $\begin{array}{l}\text {-Fluidized } \\
\text { bed reactor }\end{array}$ & $\begin{array}{l}\text { This } \\
\text { work }\end{array}$ \\
\hline
\end{tabular}

${ }^{\mathrm{a} C}$ Catalyst deactivation 

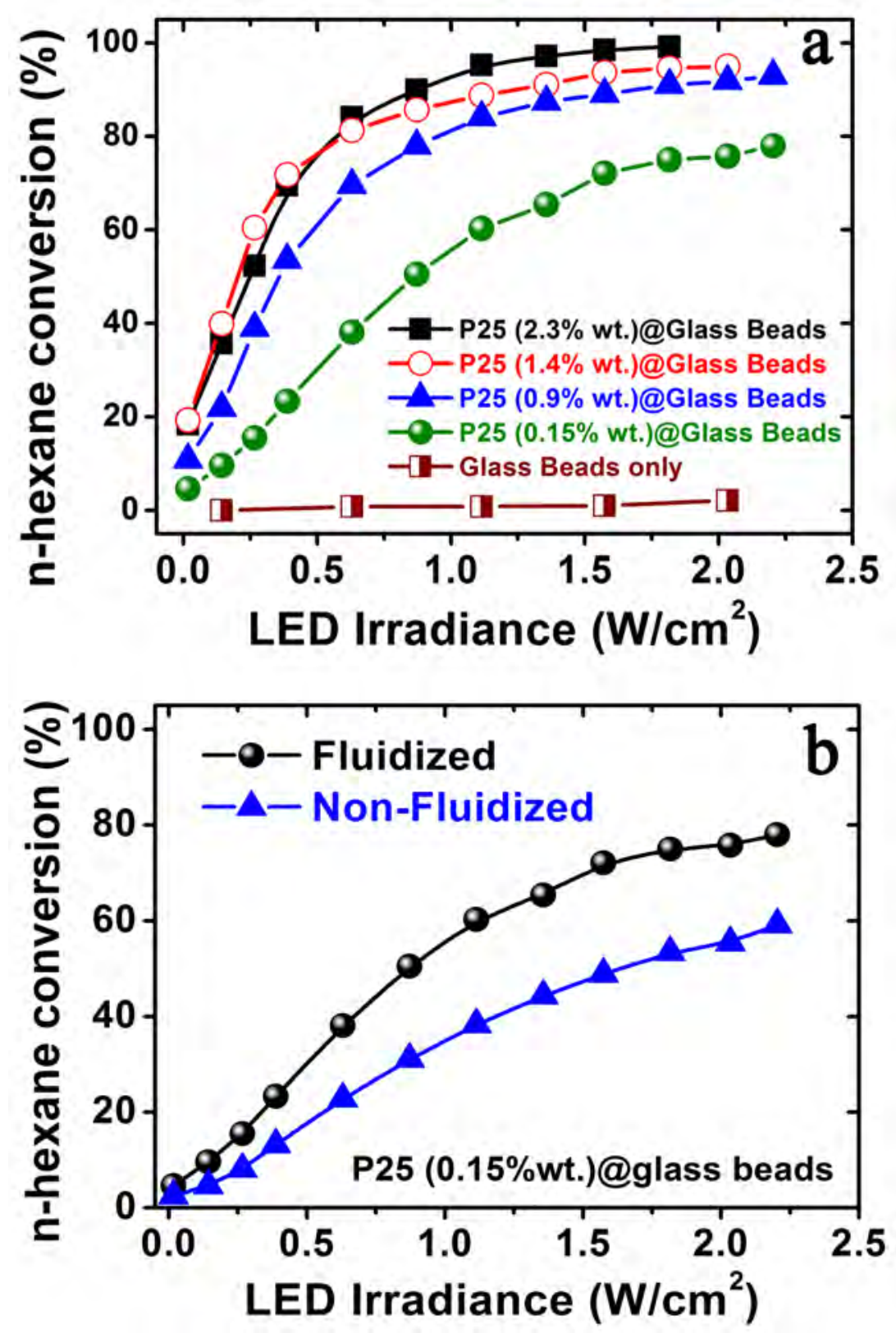

Figure 2. Photocatalytic response of the fluidized P25/glass bead at differen irradiation power during oxidation of n-hexane in air: a) Influence of the $P_{4}^{\prime}$ loading on the n-hexane light-off curves; b) Comparison of the n-hexane con different incident LED UV powers in a non-fluidized and a fluidize, respectively; (Results correspond to the catalyst with the lowest P25 loading , $\%)$. 
As already mentioned, the efficient illumination of our system seems to be one of the key factors to explain the enhanced activity towards the degradation of n-hexane. The fraction of reactor volume occupied by bubbles in the fluidized bed allows a deeper penetration of light into the bed[54, 55]. Vorontsov et al.[39] showed that a vibrofluidized bed was $26 \%$ more active than a granular fixed bed for acetone oxidation and Nelson et al.[41] detected an increase in $\mathrm{CO}_{2}$ production rates of $80 \%$ in the fluidized bed compared to packed bed reactor for methanol oxidation. In our case, due to the use of high power LEDs, practically the whole bed is irradiated so the molecules adsorbed on the surface of the catalyst are continuously illuminated facilitating the photocatalytic reaction. Furthermore, the fast axial and radial mixing promoted by the bubbling fluidization regime not only provides good heat transfer rates (thus avoiding the generation of hotter and colder regions in the reactor) but also a continuous renewal of the catalyst in the more intensely illuminated regions of the bed.

Another key factor to be considered relates to the illumination supplied by the high radiance LEDs in this work. It is expected to provide a better efficiency compared to classic broad-band lamps used in traditional photocatalysis (Table 1) that typically are within a few $\mathrm{mW} / \mathrm{cm}^{2}$ range. Also, the energy consumption of this broad-band lamps are usually in the range of hundreds of watts while in the case of the LEDs only a few watts are enough to get a high irradiance output. For most powdered materials and wavelengths ranges, traditional light sources are not able to provide illumination of the photocatalyst beyond the first few particle monolayers of the catalyst bed, and therefore thin catalyst layers are typically used in photocatalytic reactors[12, 16]. In contrast, our LED system configuration (Figure 1a-1b) is able to deliver energies up to 2200 $\mathrm{mW} / \mathrm{cm}^{2}$ providing maximum penetration of light within the whole thickness of the reactor bed $(0.5 \mathrm{~cm}$ in our case). It is also worth mentioning that all the light power 
produced by the LEDs is emitted within a very narrow spectral window of $40 \mathrm{~nm}$ centered at $365 \mathrm{~nm}$, again in contrast with the much wider fraction typically provided by conventional light sources. This means that a large proportion of the photons generated will have the energy to overcome the bandgap of the semiconductor. In addition, light penetration deepens after fluidizing the photocatalytic bed as shown by the higher conversions achieved in Figure $2 \mathrm{~b}$ for the fluidized bed reactor. While a high activity can be achieved with a fixed bed configuration (Figure $2 b$ ), probably because the transparent nature of the glass beads used to support the catalyst, the conversion for the

same flow rate and LED power density are ca. 20 percentage points higher for the fluidized bed reactor in most of the interval explored. This can be attributed to the deeper penetration of light in a bubbling fluidized bed, as a consequence of the presence of voids (bubble phase) and also the wider spaces among particles in the emulsion phase, compared to a fixed bed and it is in good agreement with the literature discussed before for other photocatalytic fluidized bed reactors[39, 41].

\subsection{Evaluation of the catalyst stability}

One of the major drawbacks reported with the use of $\mathrm{TiO}_{2}$-based catalysts towards the total oxidation of VOCs is related with deactivation issues. This problem has been primarily attributed to the formation of physisorbed by-products that compete with the active catalytic sites[29]. In this work we performed a stability experiment for several hours for one of the intermediate loadings to ensure that the catalyst was stable for extended periods of operation (Figure 3a). We postulate that this stability stems from the absence of side by-products in the reaction, which is in agreement with the carbon balance of the process that shows values close to 1 for each point. A likely factor contributing to the stability of this operation has to do with the fluidization of the catalyst particles (and any adsorbed species on them). This regime leads to higher 
irradiation exposures in areas close to the reactor wall. Besides, multiple consecutive light on/off cycling experiments further confirmed that the catalyst performance was stable and the time response to reach full conversion after turning on the LEDs remained extremely short (almost instantaneous) (Figure 3b). This latter result was in agreement with the hypothesized irradiation efficacy in our photocatalytic reactor configuration. Analogous conversion rates were also observed for the degradation of MEK in the presence of fluidized-bed flat reactors irradiated with UV-LEDs[44]. The operational stability can be also attributed to the low attrition rates observed under the experimental conditions developed in this work. Flakker et al. studied the attrition produced in a fluidized bed reactor finding that fine particles favored less carry over than larger ones[56]. We measured nanoparticle emission rates from the fluidized bed using an on-line nanoparticle counter (Figure S5). The loss of nanoparticles in the exit flow from the fluidized bed was negligible (typically around 40 nanoparticles $/ \mathrm{cm}^{3}$ in the 0-50 $\mathrm{nm}$ range and only 7 nanoparticles $/ \mathrm{cm}^{3}$ in the larger than $300 \mathrm{~nm}$ range), meaning that several thousand hours of fluidization would be needed to accumulate a loss of $1 \%$ of the catalyst mass.

Finally, a series of additional control experiments, were performed to ensure the absence of spurious effects (Figure 3c-3d). First, the reaction using uncoated glass spheres as the bed of catalyst showed that no conversion occurred even though some increase in temperature (up to $130{ }^{\circ} \mathrm{C}$ under $2200 \mathrm{~W} / \mathrm{cm}^{2}$ ) could be observed as a result of the absorption of light by the glass beads (Figure 2a). Furthermore, in order to assess the activity at different LED irradiation wavelengths, a series of reaction experiments was carried out with other high power LEDs ranging from 405 to $940 \mathrm{~nm}$. As expected, the activity of the catalyst sharply decreased in the visible and IR region of the spectrum due to the high bandgap of $\mathrm{TiO}_{2}$ (Figure 3c-3d). 

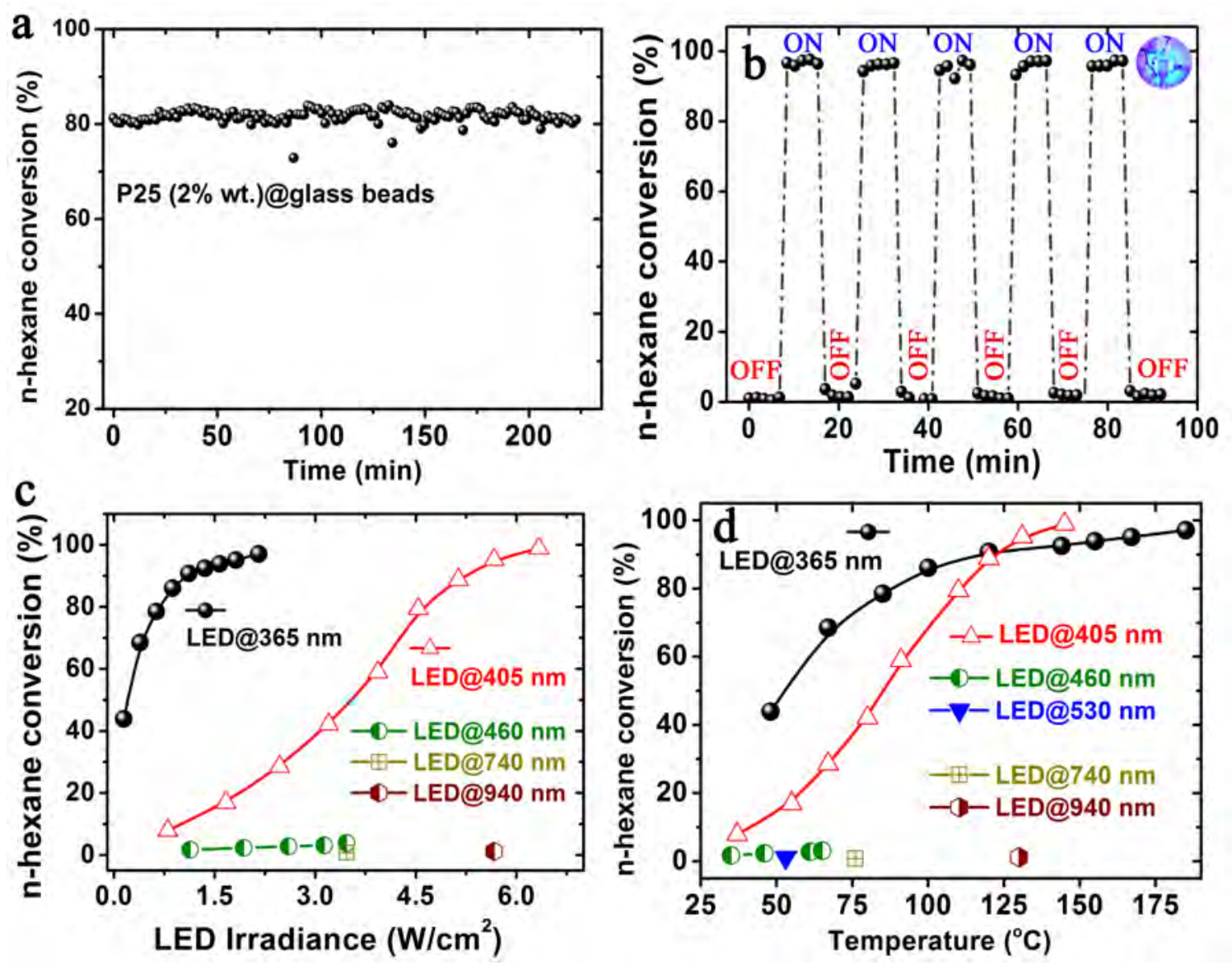

Figure 3. Evaluation of the photocatalyst for the oxidation of n-hexane: a) Stability of the catalyst under continuous operation under $365 \mathrm{~nm}$ light $\left(0,87 \mathrm{~W} / \mathrm{cm}^{2}\right)$; b) Stability of the catalyst in cyclic operation: On-Off transient experiments under $365 \mathrm{~nm}$ light (2,2 $\left.W / \mathrm{cm}^{2}\right)$; c) n-hexane conversion curves upon irradiation at different LED wavelengths and power. Due to technical limitations in the LEDs not all the irradiance points can be reproduced with every wavelength; d) n-hexane conversion curves under different LED wavelengths expressed in terms of the reaction temperature achieved within the photocatalytic bed. In the case of $530 \mathrm{~nm}$ wavelength that value is achieved at maximum LED power $(23 \mathrm{~W})$, that's why no more points are present in the graph.

The spectral width of the LED used is around $40 \mathrm{~nm}$, therefore the $405 \mathrm{~nm}$ LED still provided enough energy to excite the bandgap of the $\mathrm{TiO}_{2}$ and achieved the same 
conversion as the $365 \mathrm{~nm}$ LED, although at the expense of higher irradiation (Figure 3c). However, when longer wavelengths were tested, a negligible conversion of $n$ hexane was achieved since the incident photons were not energetic enough to overcome the P25 bandgap (Figure 3c-3d). It is also interesting to notice that despite of the temperature increase detected while irradiating with all the LED wavelengths (Figure 3d), the thermal effects on the n-hexane conversion were negligible. The activity of the catalyst at wavelengths of $460 \mathrm{~nm}$ or above was negligible, even at temperatures exceeding of $125^{\circ} \mathrm{C}$. This further supported the pure photocatalytic nature of the reaction process and discarded any photothermally-induced contributions.

\section{Conclusions}

A LED-illuminated fluidized bed reactor appears as a highly efficient system to achieve photocatalytic VOC abatement. The internal recirculation provided by the bubbling regime provides continuous renewal of the catalyst in the intensely illuminated regions of the reactor, resulting in a high average illumination of the catalyst. Additionally, the catalyst is deposited as dispersed islands on the surface of transparent glass spheres, which favours penetration of light into the bed compared to opaque supports. The glass spheres provide an easy, smooth fluidization in the bubbling regime.

This intense illumination is vital to the stability of the catalyst as it provides complete oxidation of the n-hexane, preventing the accumulation of fouling by-products on the catalyst surface. The system developed was able to fully oxidize hexane in air using only a few milligrams of catalyst and short contact times[16, 42], with excellent performance in terms of specific reaction rates compared to other photocatalytic systems reported in the literature for VOC abatement. The high stability of the catalyst under continuous and cyclic operation and the fact that photooxidation is carried under 
LED illumination with a low total input of energy, makes the system highly interesting for environmental applications. The evaluation of additional variables such as the influence of water vapour or the specific interaction with other aromatic VOC species represents a challenging subject for forthcoming research with this LED-assisted photoreactor with fluidized-bed configuration.

\section{Acknowledgements}

Financial support from MINECO (Spain) with projects CTQ2016-77147-R and CTQ2016-79419-R and the CIBER-BBN is gratefully acknowledged. We also acknowledge the support from HECTOR project. The synthesis of materials has been performed by the Platform of Production of Biomaterials and Nanoparticles of the NANOBIOSIS ICTS, more specifically by the Nanoparticle Synthesis Unit of the CIBER in Bioengineering, Biomaterials \& Nanomedicine (CIBER-BBN). The SEM studies were conducted at the Laboratorio de Microscopias Avanzadas, Instituto de Nanociencia de Aragon, Universidad de Zaragoza, Spain.

\section{References}

[1] T. Dutta, K.H. Kim, M. Uchimiya, P. Kumar, S. Das, S.S. Bhattacharya, J. Szulejko, The micro-environmental impact of volatile organic compound emissions from largescale assemblies of people in a confined space, Environ. Res., 151 (2016) 304-312.

[2] K.H. Kim, P. Kumar, J.E. Szulejko, A.A. Adelodun, M.F. Junaid, M. Uchimiya, S. Chambers, Toward a better understanding of the impact of mass transit air pollutants on human health, Chemosphere, 174 (2017) 268-279.

[3] H. Maleki, Recent advances in aerogels for environmental remediation applications: A review, Chem. Eng. J., 300 (2016) 98-118.

[4] M. Smielowska, M. Marc, B. Zabiegala, Indoor air quality in public utility environments-a review, Environ. Sci. Pollut. Res., 24 (2017) 11166-11176.

[5] I. Dhada, M. Sharma, P.K. Nagar, Quantification and human health risk assessment of by-products of photo catalytic oxidation of ethylbenzene, xylene and toluene in indoor air of analytical laboratories, Journal of Hazardous Materials, 316 (2016) 1-10. 
[6] S. Zalamea, M.P. Pina, A. Villellas, M. Menendez, J. Santamaria, Combustion of Volatile Organic Compounds over mixed-regime catalytic membranes, React. Kinet. Catal. L., 67 (1999) 13-19.

[7] R. Mevel, K. Chatelain, P.A. Boettcher, G. Dayma, J.E. Shepherd, Low temperature oxidation of n-hexane in a flow reactor, Fuel, 126 (2014) 282-293.

[8] N. Burgos, M. Paulis, M.M. Antxustegi, M. Montes, Deep oxidation of VOC mixtures with platinum supported on Al2O3/Al monoliths, Appl. Catal. B-Environ., 38 (2002) 251-258.

[9] C. Cellier, S. Lambert, E.M. Gaigneaux, C. Poleunis, V. Ruaux, P. Eloy, C. Lahousse, P. Bertrand, J.P. Pirard, P. Grange, Investigation of the preparation and activity of gold catalysts in the total oxidation of n-hexane, Appl. Catal. B-Environ., 70 (2007) 406-416.

[10] V. Szabo, M. Bassir, J.E. Gallot, A. Van Neste, S. Kaliaguine, Perovskite-type oxides synthesised by reactive grinding - Part III. Kinetics of n-hexane oxidation over LaCo(1-x)FexO3, Appl. Catal. B-Environ., 42 (2003) 265-277.

[11] L. Uson, M.G. Colmenares, J.L. Hueso, V. Sebastian, F. Balas, M. Arruebo, J. Santamaria, VOCs abatement using thick eggshell Pt/SBA-15 pellets with hierarchical porosity, Catal. Today, 227 (2014) 179-186.

[12] W. Choi, J.Y. Ko, H. Park, J.S. Chung, Investigation on TiO2-coated optical fibers for gas-phase photocatalytic oxidation of acetone, Appl. Catal. B-Environ., 31 (2001) 209-220.

[13] J.L. Hueso, J. Cotrino, A. Caballero, J.P. Espinos, A.R. Gonzalez-Elipe, Plasma catalysis with perovskite-type catalysts for the removal of $\mathrm{NO}$ and $\mathrm{CH} 4$ from combustion exhausts, J. Catal., 247 (2007) 288-297.

[14] U. Roland, M. Kraus, F. Holzer, U. Trommler, F.D. Kopinke, Selective dielectric heating for efficient adsorptive-catalytic cleaning of contaminated gas streams, Appl. Catal. A-Gen., 474 (2014) 244-249.

[15] J. Fernandez-Catala, A. Berenguer-Murcia, D. Cazorla-Amoros, Photocatalytic Oxidation of VOCs in Gas Phase Using Capillary Microreactors with Commercial TiO2 (P25) Fillings, Materials, 11 (2018) 10.

[16] B.M. da Costa, A.L.P. Araujo, G.V. Silva, R.A.R. Boaventura, M.M. Dias, J.C.B. Lopes, V.J.P. Vilar, Intensification of heterogeneous $\mathrm{TiO} 2$ photocatalysis using an innovative micro-meso-structured-photoreactor for n-decane oxidation at gas phase, Chem. Eng. J., 310 (2017) 331-341.

[17] R.A.R. Monteiro, S.M. Miranda, C. Rodrigues-Silva, J.L. Faria, A.M.T. Silva, R.A.R. Boaventura, V.J.P. Vilar, Gas phase oxidation of n-decane and PCE by photocatalysis using an annular photoreactor packed with a monolithic catalytic bed coated with P25 and PC500, Appl. Catal. B-Environ., 165 (2015) 306-315.

[18] U.L. Rochetto, E. Tomaz, Degradation of volatile organic compounds in the gas phase by heterogeneous photocatalysis with titanium dioxide/ultraviolet light, J. Air Waste Manage. Assoc., 65 (2015) 810-817.

[19] R. Sharmin, M.B. Ray, Application of ultraviolet light-emitting diode photocatalysis to remove volatile organic compounds from indoor air, J. Air Waste Manage. Assoc., 62 (2012) 8.

[20] D.S. Tsoukleris, T. Maggos, C. Vassilakos, P. Falaras, Photocatalytic degradation of volatile organics on TiO2 embedded glass spherules, Catal. Today, 129 (2007) 96101.

[21] Y. Boyjoo, H.Q. Su, J. Liu, V.K. Pareek, S.B. Wang, A review on photocatalysis for air treatment: From catalyst development to reactor design, Chem. Eng. J., 310 (2017) 537-559. 
[22] A. Aziz, K.S. Kim, Synergistic effect of UV pretreated Fe-ZSM-5 catalysts for heterogeneous catalytic complete oxidation of VOC: A technology development for sustainable use, Journal of Hazardous Materials, 340 (2017) 351-359.

[23] A. Fujishima, K. Honda, Electrochemical photolysis of water at a semiconductor electrode, Nature, 238 (1972) 37-+.

[24] R.A.R. Monteiro, F.V.S. Lopes, A.M.T. Silva, J. Angelo, G.V. Silva, A.M. Mendes, R.A.R. Boaventura, V.J.P. Vilar, Are TiO2-based exterior paints useful catalysts for gas-phase photooxidation processes? A case study on n-decane abatement for air detoxification, Appl. Catal. B-Environ., 147 (2014) 988-999.

[25] C.Y. Wu, Y.H. Yue, X.Y. Deng, W.M. Hua, Z. Gao, Investigation on the synergetic effect between anatase and rutile nanoparticles in gas-phase photocatalytic oxidations, Catal. Today, 93-5 (2004) 863-869.

[26] M. Keshmiri, T. Troczynski, M. Mohseni, Oxidation of gas phase trichloroethylene and toluene using composite sol-gel $\mathrm{TiO} 2$ photocatalytic coatings, Journal of Hazardous Materials, 128 (2006) 130-137.

[27] P.A. Deveau, F. Arsac, P.X. Thivel, C. Ferronato, F. Delpech, J.M. Chovelon, P. Kaluzny, C. Monnet, Different methods in TiO2 photodegradation mechanism studies: Gaseous and TiO2-adsorbed phases, Journal of Hazardous Materials, 144 (2007) 692697.

[28] A.G. Kontos, A. Katsanaki, T. Maggos, V. Likodimos, A. Ghicov, D. Kim, J. Kunze, C. Vasilakos, P. Schmuki, P. Falaras, Photocatalytic degradation of gas pollutants on self-assembled titania nanotubes, Chemical Physics Letters, 490 (2010) 58-62.

[29] C.T. Brigden, S. Poulston, M.V. Twigg, A.P. Walker, A.J.J. Wilkins, Photooxidation of short-chain hydrocarbons over titania, Applied Catalysis B-Environmental, 32 (2001) 63-71.

[30] J.O. Saucedo-Lucero, G. Quijano, S. Arriaga, R. Munoz, Hexane abatement and spore emission control in a fungal biofilter-photoreactor hybrid unit, Journal of Hazardous Materials, 276 (2014) 287-294.

[31] A.K. Boulamanti, C.J. Philippopoulos, Photocatalytic degradation of C-5-C-7 alkanes in the gas-phase, Atmos. Environ., 43 (2009) 3168-3174.

[32] C. McCullagh, N. Skillen, M. Adams, P.K.J. Robertson, Photocatalytic reactors for environmental remediation: a review, J. Chem. Technol. Biotechnol., 86 (2011) 10021017.

[33] A. Manassero, M.L. Satuf, O.M. Alfano, Photocatalytic reactors with suspended and immobilized TiO2: Comparative efficiency evaluation, Chem. Eng. J., 326 (2017) 29-36.

[34] G.E. Imoberdorf, A.E. Cassano, H.A. Irazoqui, O.M. Alfano, Optimal design and modeling of annular photocatalytic wall reactors, Catal. Today, 129 (2007) 118-126.

[35] Q.J. Geng, Q.M. Wang, Y.C. Zhang, L.T. Wang, H.Q. Wang, Photocatalytic degradation intrinsic kinetics of gaseous cyclohexane in a fluidized bed photocatalytic reactor, Res. Chem. Intermed., 39 (2013) 1711-1726.

[36] P.L. Yue, F. Khan, L. Rizzuti, Photocatalytic ammonia-sunthesis in a fluidized-bed reactor, Chem. Eng. Sci., 38 (1983) 1893-1900.

[37] L.A. Dibble, G.B. Raupp, Fluidized-bed photocatalytic oxidation of trichloroethylene in contaminated airstreams, Environ. Sci. Technol., 26 (1992) 492495.

[38] M.L. Zhang, T.C. An, J.M. Fu, G.Y. Sheng, X.M. Wang, X.H. Hu, X.J. Ding, Photocatalytic degradation of mixed gaseous carbonyl compounds at low level on 
adsorptive $\mathrm{TiO} 2 / \mathrm{SiO} 2$ photocatalyst using a fluidized bed reactor, Chemosphere, 64 (2006) 423-431.

[39] A.V. Vorontsov, E.N. Savinov, P.G. Smirniotis, Vibrofluidized- and fixed-bed photocatalytic reactors: case of gaseous acetone photooxidation, Chem. Eng. Sci., 55 (2000) 5089-5098.

[40] T.H. Lim, S.D. Kim, Trichloroethylene degradation by photocatalysis in annular flow and annulus fluidized bed photoreactors, Chemosphere, 54 (2004) 305-312.

[41] R.J. Nelson, C.L. Flakker, D.S. Muggli, Photocatalytic oxidation of

methanol using titania-based fluidized beds, Appl. Catal. B-Environ., 69 (2007) 7.

[42] T. Van Gerven, G. Mul, J. Moulijn, A. Stankiewicz, A review of intensification of photocatalytic processes, Chem. Eng. Process., 46 (2007) 781-789.

[43] F. Khodadadian, M.W. de Boer, A. Poursaeidesfahani, J.R. van Ommen, A.I. Stankiewicz, R. Lakerveld, Design, characterization and model validation of a LEDbased photocatalytic reactor for gas phase applications, Chem. Eng. J., 333 (2018) 456466.

[44] M. Hajaghazadeh, V. Vaiano, D. Sannino, H. Kakooei, R. Sotudeh-Gharebagh, P. Ciambelli, Heterogeneous photocatalytic oxidation of methyl ethyl ketone under UV-A light in an LED-fluidized bed reactor, Catal. Today, 230 (2014) 79-84.

[45] I. Julian, J. Herguido, M. Menendez, Experimental and simulated solids mixing and bubbling behavior in a scaled two-section two-zone fluidized bed reactor, Chem. Eng. Sci., 143 (2016) 240-255.

[46] I. Julian, J. Herguido, M. Menendez, Particle Mixing in a Two-Section Two-Zone Fluidized Bed Reactor. Experimental Technique and Counter-Current Back-Mixing Model Validation, Ind. Eng. Chem. Res., 52 (2013) 13587-13596.

[47] M. Hajaghazadeh, V. Vaiano, D. Sannino, H. Kakooei, R. Sotudeh-Gharebagh, Influence of operating parameters on gas phase photocatalytic oxidation of methylethyl-ketone in a light emitting diode (LED)-fluidized bed reactor, Korean J. Chem. Eng., 32 (2015) 636-642.

[48] N. Quici, M.L. Vera, H. Choi, G.L. Puma, D.D. Dionysiou, M.I. Litter, H. Destaillats, Effect of key parameters on the photocatalytic oxidation of toluene at low concentrations in air under $254+185 \mathrm{~nm}$ UV irradiation, Applied Catalysis BEnvironmental, 95 (2010) 312-319.

[49] X.Y. Deng, Y.H. Yue, Z. Gao, Gas-phase photo-oxidation of organic compounds over nanosized $\mathrm{TiO} 2$ photocatalysts by various preparations, Appl. Catal. B-Environ., 39 (2002) 135-147.

[50] T.D. Pham, B.K. Lee, Selective removal of polar VOCs by novel photocatalytic activity of metals co-doped TiO2/PU under visible light, Chem. Eng. J., 307 (2017) 6373.

[51] M. Nagao, Y. Suda, ADSORPTION OF BENZENE, TOLUENE, AND CHLOROBENZENE ON TITANIUM-DIOXIDE, Langmuir, 5 (1989) 42-47.

[52] A.M. Dashliborun, R. Sotudeh-Gharebagh, M. Hajaghazadeh, H. Kakooei, S. Afshar, Modeling of the photocatalytic degradation of methyl ethyl ketone in a fluidized bed reactor of nano-TiO2/gamma-Al2O3 particles, Chem. Eng. J., 226 (2013) 59-67.

[53] R.S. Zhu, S.A. Che, X.B. Liu, S.X. Lin, G.L. Xu, F. Ouyang, A novel fluidizedbed-optical-fibers photocatalytic reactor (FBOFPR) and its performance, Appl. Catal. A-Gen., 471 (2014) 136-141.

[54] L. Rizzuti, P.L. Yue, The measurement of light transmission through an irradiated fluidized-bed, Chem. Eng. Sci., 38 (1983) 1241-1249.

[55] A. Brucato, D. Iatridis, L. Rizzuti, P.L. Yue, Modeling of light transmittance and reflectance in flat fluidized photoreactors, Can. J. Chem. Eng., 70 (1992) 1063-1070. 
[56] C.L. Flakker, D.S. Muggli, Factors affecting methanol photocatalytic oxidation and catalyst attrition in a fluidized-bed reactor, Applied Catalysis B-Environmental, 84 (2008) 706-714. 